\title{
Tensile Testing of 3D Printed Materials Made by Different Temperature
}

Jakub Pernica (ORCID: 0000-0001-9959-1776)1, Michal Sustr (ORCID: 0000-0002-3410-6888)1 ${ }^{1}$, Petr Dostal (ORCID: 0000-0001-7489- 3591)1, Martin Brabec (ORCID: 0000-0001-5575-8925)², David Dobrocky (ORCID: 0000-0003-1400-3993) $)^{3}$

${ }^{1}$ Faculty of AgriSciences, Mendel University in Brno. Zemědělská 1, 61300 Brno. Czech Republic. E-mail: xpernic2@mendelu.cz

${ }^{2}$ Faculty of Forestry and Wood Technology, Mendel University in Brno. Zemědělská 1, 61300 Brno. Czech Republic.

${ }^{3}$ Faculty of Military Technology, University of Defence in Brno. Kounicova 65, 60200 Brno. Czech Republic.

The work is focused effect of different temperature nozzle in additive manufacturing process FFF (Fused Filament Fabrication) technology for the most common materials (PLA, PETG and ABS). A standard specimen internal structure arranged $\pm 45^{\circ}$ in longitudinal print direction with $100 \%$ infill. For the exact testing are used no perimetres. The specimens were printed by minimal, middle and maximum nozzle temperature. Temperature range is given by the filament company. To ensure relevant testing materials from the same company in one colour were used. A printed specimens were testing by destructive testing method on tensile testing machine. For testing were made five specimens in one setting. Finally, were made 45 specimens for tensile testing.

Keywords: Additive manufacturing, 3D print, FDM/FFF, tensile testing, print nozzle temperature, mechanical properties.

\section{Introduction}

Additive manufacturing is a process of creating a physical model from a 3D computer model using an automated machine (3D printer). A 3D printer assembly include main parts such a frame, heat bed, step motors for linear motion in axis X, Y and Z, extruder etc. The physical model is created by slicing computer model in special software into individual layers which are gradually layered on each other. Additive manufacturing using FFF (Fused Filament Fabrication) technology uses a filament fusion process to create a physical model that creates desired product shape. The extruder and other 3D printer components are used. Thus, additive manufacturing is the opposite of conventional machining methods where the final shape of the product is achieved by removing material. The FFF 3D printers are common technology in available additive manufacturing. Product of the 3D printers can be used in many technical applications like manufacturing tooling parts, spare parts etc. In this time there are many polymer materials those can by used according to specific application. [1, 2, 3, 4].

PLA (Polyatic Acid) is one of the most widely used and easiest plastics to print by FFF 3D printers. It is a biological plastic made from eg. corn scrub. The material is poorly resistant to high temperatures (begins to soften above $60^{\circ} \mathrm{C}$ ) and poorly resistant to weathering. Composting may be possible in certain conditions $[5,6]$.
PETG is a common PET (Polyethylene Terephthalate) material with addition of Glucol that facilitates processing on a $3 \mathrm{D}$ printer. The material combines the characteristics of PLA and ABS. It is also easy to print but withstands higher temperatures and weather conditions $[2,7]$.

ABS (Acrylonytrile Butadiene Styrene) is one of the most widely used plastics in industry. It is used in automotive industry, engineering, or in production of toys such as Lego. Manufacturing on the 3D printer requires box to ensure constant printing conditions, as it is very susceptible to shrinking while printing $[2,5]$.

\section{Material and Methods}

A standard specimen was made in CAD (Computer Aided Design) system Fusion 360 and for 3D print was exported to format.stl. The 3D model in Fusion 360 was designed by ASTM D638-03. For the 3D printing was used slicer software PrusaSlicer 2.0.0 and 3D printer Prusa $3 \mathrm{mk} 3 \mathrm{~s}$. Temperature range is given by the filament company. Material PLA was printed by $190^{\circ} \mathrm{C} \pm 5^{\circ} \mathrm{C}, 210^{\circ} \mathrm{C} \pm 5^{\circ} \mathrm{C}$ and $230^{\circ} \mathrm{C} \pm 5^{\circ} \mathrm{C}$ nozzle temperature, PETG was printed by $200^{\circ} \mathrm{C} \pm 5^{\circ} \mathrm{C}$, $220^{\circ} \mathrm{C} \pm 5^{\circ} \mathrm{C}$ and $240^{\circ} \mathrm{C} \pm 5^{\circ} \mathrm{C}$ nozzle temperature, ABS was printed $190^{\circ} \mathrm{C} \pm 5^{\circ} \mathrm{C}, 210^{\circ} \mathrm{C} \pm 5^{\circ} \mathrm{C}$ and $230^{\circ} \mathrm{C} \pm 5^{\circ} \mathrm{C}$ nozzle temperatures (see Table 1 ). Accuracy of temperature nozzle is given by $3 \mathrm{D}$ printer company Prusa Research. Nozzle diameter was 0.4 $\mathrm{mm}$ and layer height $0.2 \mathrm{~mm}$ which is the mostly common setting for economical addititve manufacturing. 
In the slicing software was used default setting a little changes for optimal specimen setting. A perimeters was reduced from 2 to 0 and infill was changed from $20 \%$ to $100 \%$. Finally, 45 specimens were made for tensile testing (see Fig. 1).

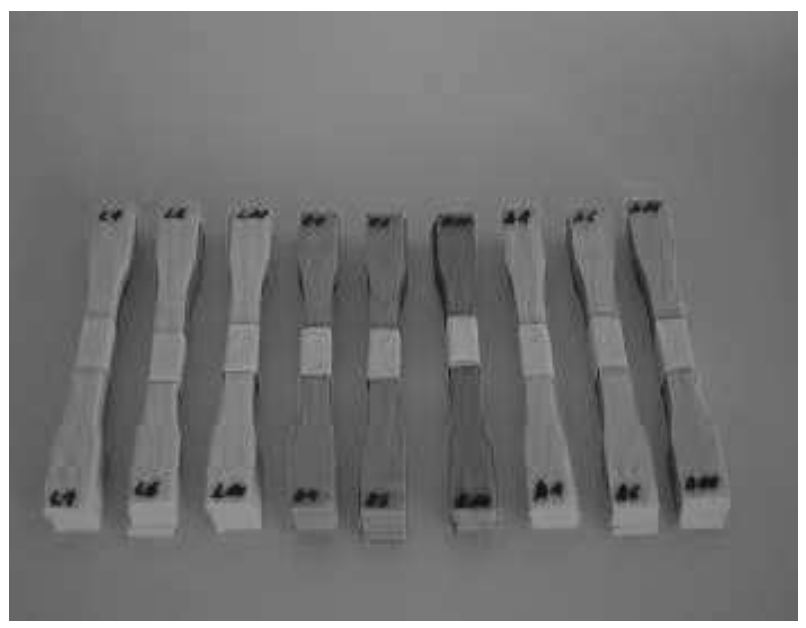

Fig. 1 Specimen ASTM D638
The specimens were tested on the tensile machine ZDM 5/51 (see Fig. 2). A tensile machine provides for measuring different materials throughout tension, compression and bending. As the main method was chosen tensile testing. A testing was made by ASTM D638-03. Direction Z-axis was moving constant speed $5 \mathrm{~mm} / \mathrm{min}$.

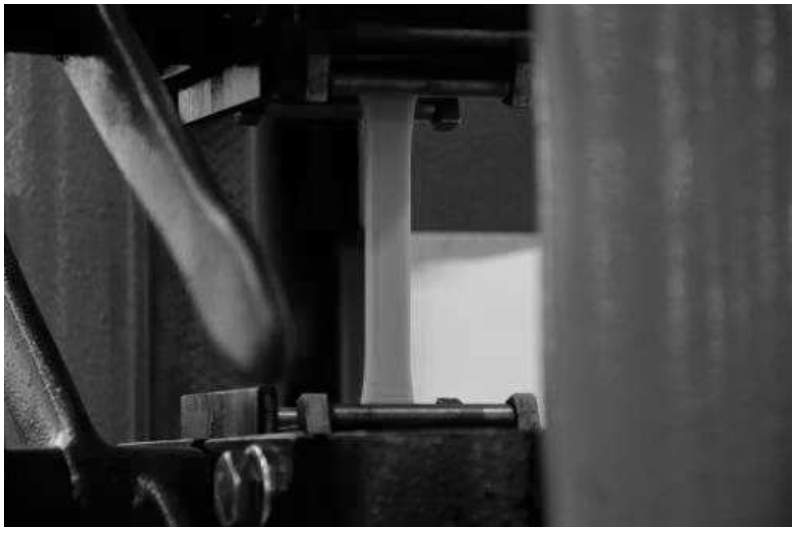

Fig. 2 Fixing specimen

Tab. 1 Characteriztion of specimens

\begin{tabular}{|c|c|c|c|c|c|c|c|c|}
\hline \multirow[b]{2}{*}{$\begin{array}{l}\text { Tempera- } \\
\text { ture nozzle }\end{array}$} & \multirow[b]{2}{*}{ Material } & \multirow[b]{2}{*}{$\begin{array}{l}\text { Number of } \\
\text { specimen }\end{array}$} & \multirow[b]{2}{*}{$\begin{array}{c}\text { Area of } \\
\text { surface } \\
{\left[\mathrm{mm}^{2}\right]}\end{array}$} & \multicolumn{4}{|c|}{ Print temperature } & \multirow[b]{2}{*}{ Note } \\
\hline & & & & $\begin{array}{c}\text { Firs } \\
\text { layer } \\
\text { bed } \\
{\left[{ }^{\circ} \mathrm{C}\right]}\end{array}$ & $\begin{array}{l}\text { Bed } \\
{\left[{ }^{\circ} \mathrm{C}\right]}\end{array}$ & $\begin{array}{c}\text { First } \\
\text { layer } \\
\text { nozzle } \\
{\left[{ }^{\circ} \mathrm{C}\right]}\end{array}$ & $\begin{array}{c}\text { Nozzle } \\
{\left[{ }^{\circ} \mathrm{C}\right]}\end{array}$ & \\
\hline Minimal & PLA & L1 - L5 & 42.48 & 70 & 70 & 190 & 190 & \\
\hline Middle & PLA & L6 - L10 & 41.76 & 70 & 70 & 210 & 210 & \\
\hline Maximum & PLA & L11 - L15 & 44.16 & 70 & 70 & 230 & 230 & \\
\hline Minimal & PETG & E1 - E5 & 44.12 & 85 & 85 & 220 & 200 & 1 \\
\hline Middle & PETG & E6 - E10 & 43.85 & 85 & 85 & 220 & 220 & 1 \\
\hline Maximum & PETG & E11 - E15 & 41.75 & 85 & 85 & 240 & 240 & 1 \\
\hline Minimal & ABS & A1-A5 & 45.29 & 100 & 100 & 210 & 190 & 1,2 \\
\hline Middle & ABS & A6 - A10 & 44.79 & 100 & 100 & 210 & 210 & 1,2 \\
\hline Maximum & ABS & A11 - A15 & 43.03 & 100 & 100 & 230 & 230 & 1,2 \\
\hline
\end{tabular}

Legend: 1 - Adjusted temperature of the first layer, 2 - print in a box

\section{Results and Discussion}

\subsection{D print process}

A material PLA is the only appropriate to print by minimal, middle and maximum nozzle temperature (see Figure 3). Material PETG and ABS do not print first layer by minimal nozzle temperature. Because of better adhesion for the first layer on bed was used glue stick Kores which is recommended by Prusa Research technical support. After usage of glue stick the problem with adhesion (by using minimal temperature) continued (see Figure 4), so finally first layer in material PETG and ABS was made by middle nozzle temperature and the rest layers were printed by minimal nozzle temperature (see Table 1). For PETG $200^{\circ} \mathrm{C} \pm 5^{\circ} \mathrm{C}$ and $\mathrm{ABS} 190^{\circ} \mathrm{C} \pm 5^{\circ} \mathrm{C}$ with maximum temperature of bed.

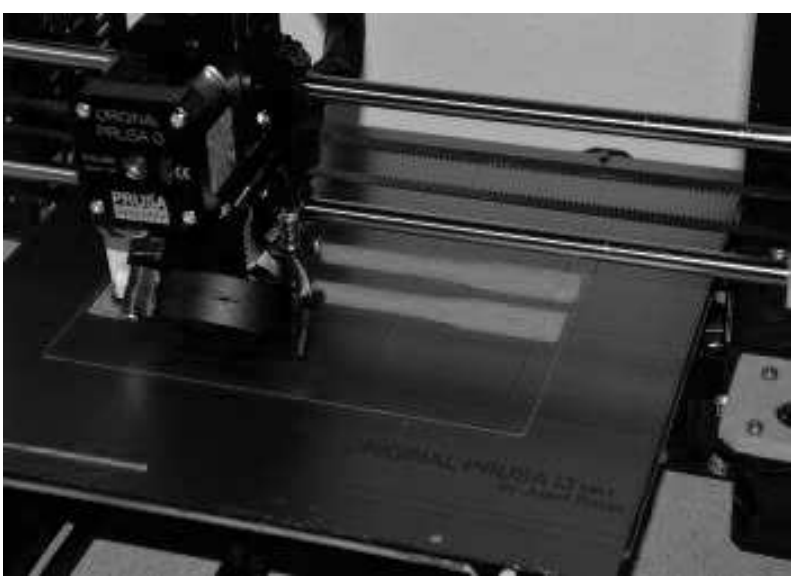

Fig. 3 3D print PLA 


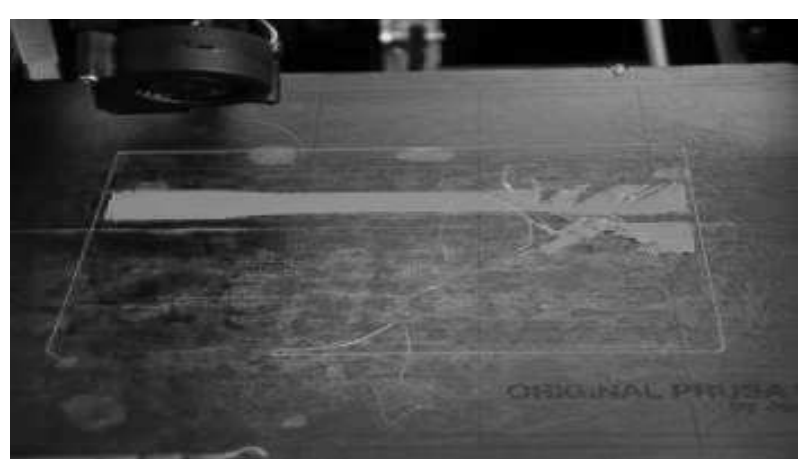

Fig. 43 print on glue stick

\subsection{Tensile testing}

For one testing were made five specimens. In real visualization of the measured values were fifteen graphs. For more clear visualization of the graphs, the measured values were statistically adjusted by average calculation method. The values of groups of five identical specimens (eg. L1, L2, ..., L5) were printed in the same time. For statistic evaluation software office 365 excel was used. The values were statistically evaluated by Anova and Tukey test.

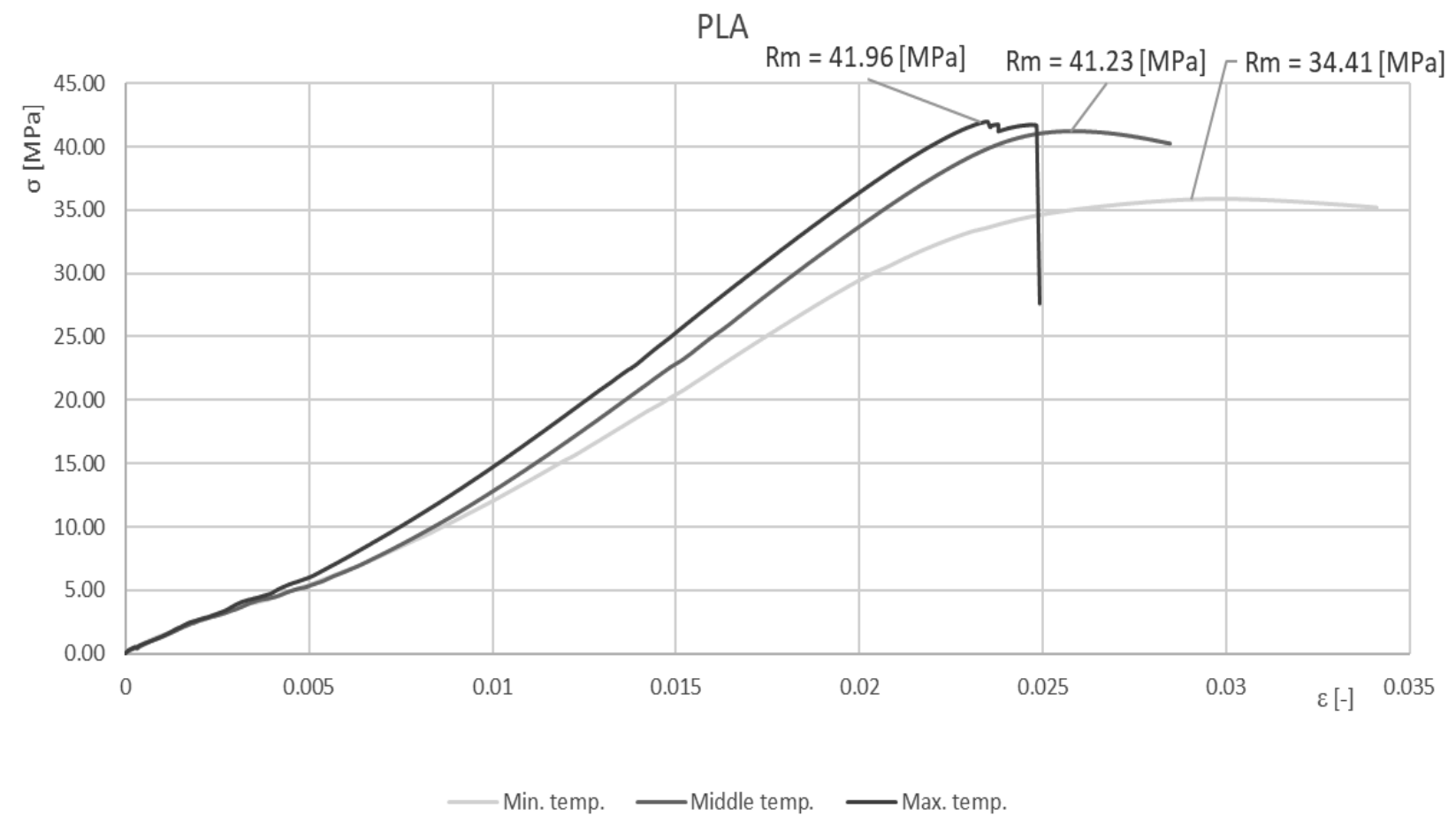

Legend: $2-\sigma-$ Stress [MPa], $\varepsilon-$ Strain [-]

Fig. 5 Tensile diagram of PLA

PLA has similar strength limits for the temperature nozzle in $210^{\circ} \mathrm{C} \pm 5^{\circ} \mathrm{C}$ and $230^{\circ} \mathrm{C} \pm 5^{\circ} \mathrm{C}$ (see Figure 5). For maximum temperature is tensile strength $(\mathrm{Rm}$ in Figure 5) $41.96 \mathrm{MPa} \pm 0.84 \mathrm{MPa}$ and middle temperature 41.23 $\mathrm{MPa}$. Printed specimen (L1 - L5) was made by $190^{\circ} \mathrm{C} \pm 5^{\circ} \mathrm{C}$ nozzle temperature and exhibits the lowest tensile strength compared to other PLA specimen 34.41 $\mathrm{MPa} \pm 3.60 \mathrm{MPa}$. The high value of standard deviation is given different values of testing specimens printed by minimal temperature. Similar results were also achieved by Frans Johansson who studied a mechanical properties of PLA materials [8]. A Stratasys company which was focused on certificateted filaments for additive manufacturing for repeatability state tensile strength $45 \mathrm{MPa}$ in $\mathrm{XZ}$ orientation [13].

PETG has the lowest tensile strength of the tested materials (see Figure 6). The highest tensile strength is obtained by specimens printed at the maximum temperature nozzle $\left(240^{\circ} \mathrm{C} \pm 5^{\circ} \mathrm{C}\right)$. Tensile strength is $24.56 \mathrm{MPa}$. The lowest tensile strength is obtained from specimens produced by the lowest temperature nozzle $\left(200^{\circ} \mathrm{C} \pm 5^{\circ} \mathrm{C}\right)$. In a publication Effect on infill density on mechanical properties of PETG part fabricated by fused deposition modelling is tensile strength $32.12 \mathrm{MPa}$ in $100 \%$ infill speciment [12]. The higher tensile strength can be manufactured with perimeters. 


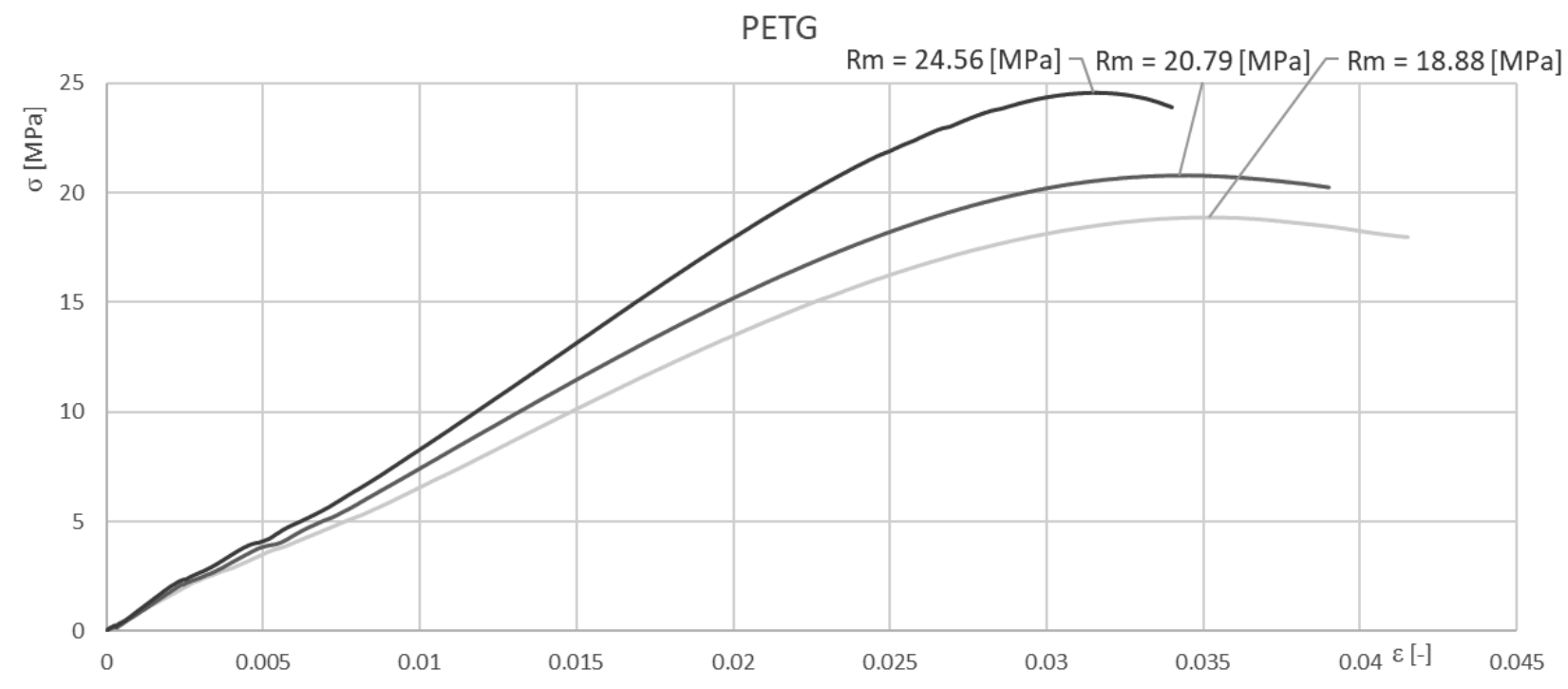

Min. temp. PETG — Middle temp. PETG — Max. temp. PETG

Legend: $3-\sigma-$ Stress $[M P a], \varepsilon-$ Strain $[-]$

Fig. 6 Tensile diagram of PETG

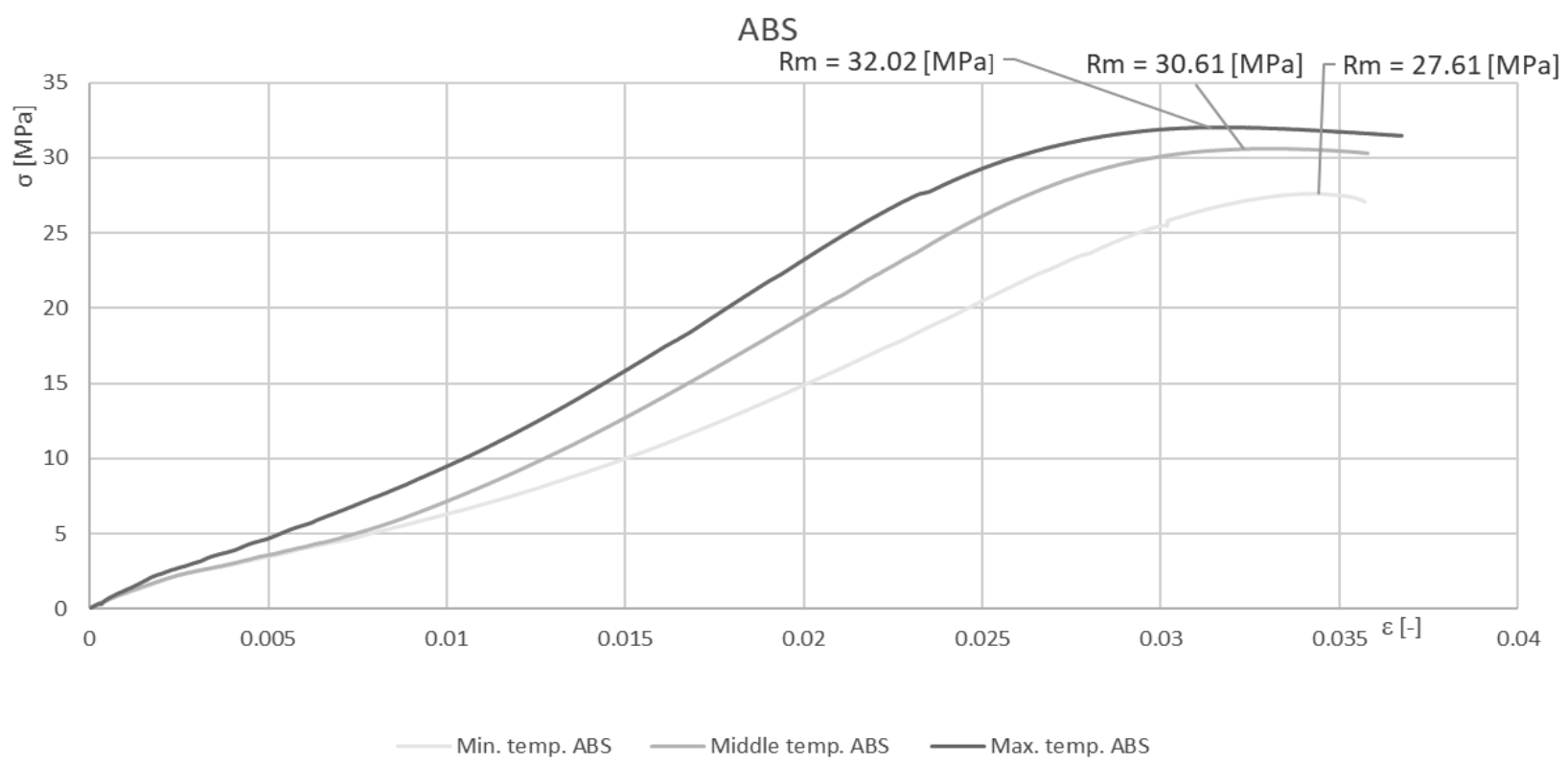

Legend: $4-\sigma-$ Stress $[M P a], \varepsilon-$ Strain $[-]$

Fig. 7 Tensile diagram of $A B S$

Testing of specimen made from ABS shows similar behaviour to specimen made from PETG (see Figure 7). It means the higher nozzle temperature during 3D printing, the higher the tensile strength of the specimen. Lowest nozzle temperature for printing was $190^{\circ} \mathrm{C} \pm 5^{\circ} \mathrm{C}$ nozzle, middle nozzle temperature for printing was $210^{\circ} \mathrm{C} \pm 5^{\circ} \mathrm{C}$ nozzle and maximum nozzle temperature for printing was $230^{\circ} \mathrm{C} \pm 5^{\circ} \mathrm{C}$. Similar tensile strenght state the Stratasys in material list for material ABS-M30. Tensile strength si for material ABS-M30 is $27.5 \mathrm{MPa}$ in ZX orintation which is similar value like lowest nozzle temperature. For orientation $\mathrm{XZ}$ is tensile strength $30.8 \mathrm{MPa}$ which is between maximum and middle nozzle temperature [14].

For measured data was predicted normal distribution. Two hypotheses were made. H0: values do not show difference, Ha: values show differences. Because is $p$ value under 0.001 (see Tabel 2) it is correct hypothesis that values show differences. 
Tab.2 Measured values

\begin{tabular}{|c|c|c|c|c|c|c|c|c|c|}
\hline $\begin{array}{l}\text { Tempera- } \\
\text { ture nozzle }\end{array}$ & Material & $\begin{array}{l}\text { Number of } \\
\text { specimen }\end{array}$ & $\begin{array}{c}\text { Tensile } \\
\text { stress } \\
{[\mathrm{MPa}]}\end{array}$ & $\begin{array}{l}\text { Disper- } \\
\text { sion } \\
{[\mathrm{MPa}]}\end{array}$ & $\begin{array}{c}p \text { value } \\
p[-]\end{array}$ & $\begin{array}{l}\text { Stand- } \\
\text { ard de- } \\
\text { viation } \\
\text { [MPa] }\end{array}$ & 1 & 2 & 3 \\
\hline Minimal & PLA & L1 - L5 & 34.41 & 12.95 & \multirow{3}{*}{ 8.15E-04 } & 3.60 & & \multirow[t]{3}{*}{$* * * *$} & \\
\hline Middle & PLA & L6 - L10 & 41.23 & 0.86 & & 0.93 & **** & & \\
\hline Maximum & PLA & L11 - L15 & 41.89 & 0.70 & & 0.83 & **** & & \\
\hline Minimal & PETG & $\mathrm{E} 1-\mathrm{E} 5$ & 18.88 & 0.27 & \multirow{3}{*}{$<0.001$} & 0.52 & ***** & \multirow{3}{*}{ ***** } & \multirow[b]{3}{*}{$* * * *$} \\
\hline Middle & PETG & E6 - E10 & 20.79 & 0.10 & & 0.31 & & & \\
\hline Maximum & PETG & E11 - E15 & 24.56 & 0.48 & & 0.69 & & & \\
\hline Minimal & ABS & A1 - A5 & 27.61 & 4.36 & \multirow{3}{*}{$<0.001$} & 2.09 & & \multirow[t]{3}{*}{ ***** } & \\
\hline Middle & ABS & A6 - A10 & 30.61 & 0.10 & & 0.32 & **** & & \\
\hline Maximum & ABS & A11 - A15 & 32.02 & 0.24 & & 0.49 & **** & & \\
\hline
\end{tabular}

In right part of the table (see Table 2) we can see group differences values $(1,2,3)$ of Tukey test method. Materilas PLA and ABS show that there are statistically significant differences between specimens printed by minimal temperature nozzle and the other specimens. Material PETG shows statistically significant differneces between all specimens.

\subsection{Specimens}

In the figures below, interesting tear fractures after the tensile test are shown. It is apparent that the individual layers do not comletely melt at low temeperatures (see Figure 8). A tensile stress is thus transmitted by the individual plastic fibers. It is also apparent that the higher nozzle temperature during manufacturing is better for melting of the individual layers and thus the specimens has higher strength. According to research by Frans Johansson [9] melting layers are not important only for the nozzle temperature, but also the speed of printing is important.

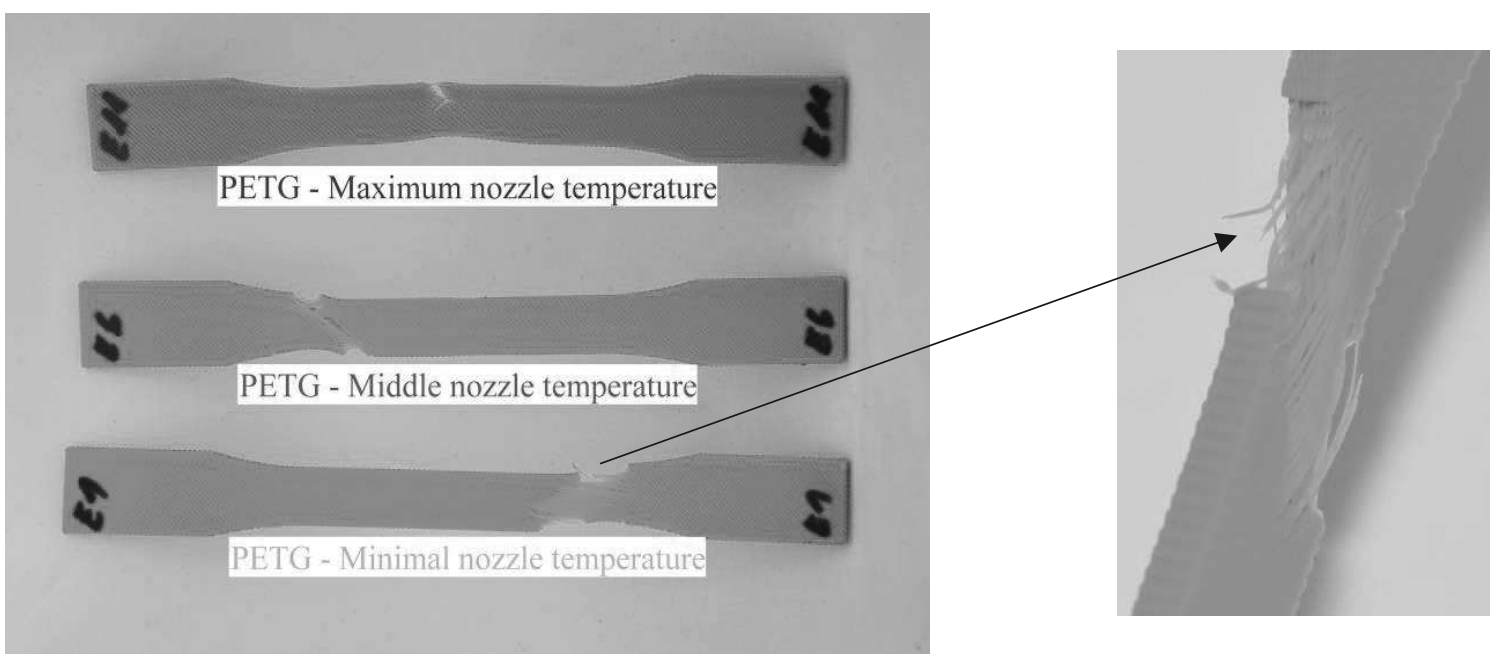

Fig. 8 Fracture specimen PETG

Specimens made of ABS materials show change of color which is probably depended on tensile stress (see Figure 9). This is most noticeable on a specimen that has been printed by the highest recommended nozzle temperature. For other specimens that do not show up any provable color changes in the tensile test the Digital Image Correlation (DIC) method might be used. DIC is modern optical methods for measuring deformations. On specimens are applicated contrast color which is very important for computer analyzing. Measure and software components work on comparing digital displacement position and photographs. It is very effective method for measuring tensile progress in time [10,11].

The research has shown that there are differencess between PLA, PETG and ABS. PLA shows the highest tensile strength of the measured values 41.96 $\mathrm{MPa}$. The lowest tensile strength is in case of material PETG which has been printed by minimal temperature nozzle. Compared to traditional engineering materials like steel E295 (ČSN 41 1500) is tensile strength $500 \mathrm{MPa}$ [8]. The tensile strength of measured plastic materials is from $18.88 \mathrm{MPa}$ to 41.96 $\mathrm{MPa}$. 


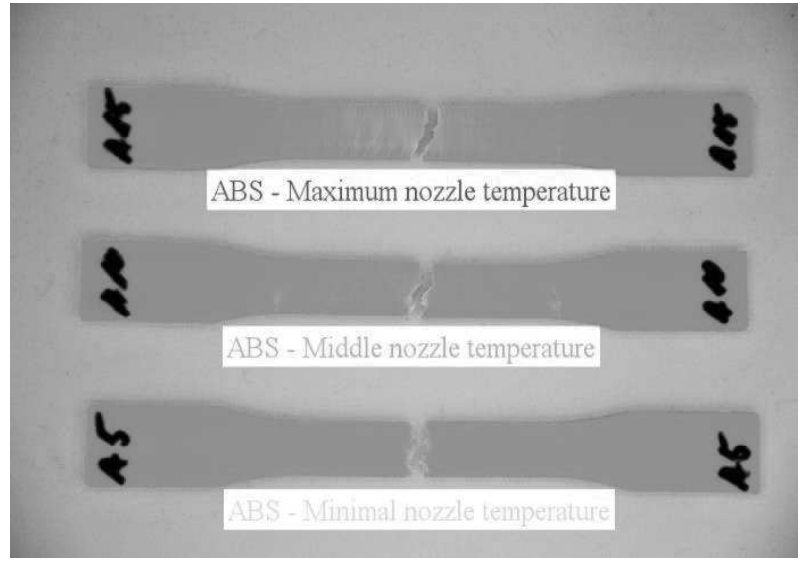

Fig. 9 Fracture specimen $A B S$

In statistical evaluation of result between all tested samples are not clear statistical differences in tensile strength and temperature nozzle. It can be longitudinal print direction. For more broad research it will be useful to print specimens in vertical print direction by same print setting [2]. Statistical differences can be significant results and might be a good progres in the following research.

\section{Conclusion}

The right choice of the temperature of 3D print is very important. The right setting of temperatures while printing might have influence on the final product. The producer indicates minimal and maximal printing temperature and it might be assumed that in the range of the indicated temperatures the mechanic qualities of the product might be constant or have minimal deviation. Based on the performed experiment and evaluated data there were discovered many differences in strenght in draughts using higher and lower temperature limit indicated by producer. The draught-proofings showed up that higher temperature causes better mechanic qualities of products. With the decreasing of the printing temparature the final strenght of draughts of specimens decreases as well. This fact is documented on the graphs from draught-proofing for materials such as PLA, PETG and ABS. All these materials have responded to the change of printing temperatures in the same trend.

Based on proven experiments, it can beproved that in order to obtain the highest possible mechanical resistance of $3 \mathrm{D}$ prints, it is appropriate to use the upper limits of the manufacturer's recommended temperatures. However, it should be noted that mechanical qualities are not always the primary requirement and in other cases lower resistance is sufficient. However, during the large-scale production the main issue will be economic analysis and reduce of costs. It is clear that energy requirements increase to achieve higher temperatures and that's why the printing costs increase as well. It is recommended to perform lower temperature of printing for the purposes of less strength applications.

The described experiment gives individual strength dependences at different temperatures and thanks to the presented results the user can choose the optimal ratio between strength and economic costs depending on the scope of production and on the basis of strength requirements.

\section{Acknowledgement}

The research has been supported by the project TG 02010074 sub-project: Holding and cooking case and the specific research project 2020 'SV20216" at the Department of Mechanical Engineering, University of Defence in Brno.

\section{References}

[1] HAUSMAN, K., HORNE, R. (2014). 3D printing for dummies. $2^{\text {nd }}$ ed., New Jersey: John Wiley $\&$ Sons, Inc.

[2] HLUCHÝ, M., KOLOUCH, J. (2007). Strojirenská technologie 1: Nauka o materiálu. $4^{\text {th }}$ ed., Praha: Scientia.

[3] DVORAK, K., ZARYBNICKA, L., DVORAKOVA, J. (2019). Quality Parameters of 3D print Products by the DMLS Method. Manufacturing Technology, Vol. 19, No. 2, 2019, p. 209-215.

[4] RAZ, K. (2019). Advantages of Aditive Technologies Usage in Design of Cooling Channels. Manufacturing Technology, Vol. 19, No. 1, 2019, p. 135-138.

[5] KLOSKI, W.L., KLOSKI, N. (2017). Začnáme s 3D tiskem. $1^{\text {st }}$ ed., Brno: Computer Press.

[6] KROTKÝ, J., HONZÍKOVÁ, J., MOC, P. (2016). Deformation of Print PLA Material Depending on the Temperature of Reheating Printing Pad. Manufacturing Technology, Vol. 16, No. 1, 2019, p. 136-140.

[7] SVOBODA, P., BRANDEJS, J. (2013). Výbèry z. norem pro konstrukéni cvičení. $5^{\text {th }}$ ed., Brno: Cerm.

[8] STŘÍTECKÝ, J., PRŮŠA, J., BACH, M. (2019). Základy 3D tisku s Josefem Prǔšou [online]. Praha: Prusa Research s.r.o. Available at: http://www.prusa3d.cz/kniha-zaklady-3Dtisku-josefa-prusi. [2019-08-29].

[9] JOHANSSON, F. (2016). Optimizing Fused Filament Fabrication 3D printing for durability. Master's thesis, Blekinge Institute of Technology. 
[10] McCORMIC, N., LORD, J. (2010). Digital Imagine Correlation. Materials Today, Vol. 13, No. 12, 2010, p. 52-54.

[11] QIONG, L., YOURONG, Y., LEILEI, C. (2016). Computer Visual Measurement Technology and Algorithm Simulation for the Assembly of Large Aircraft Parts. Manufacturing Technology, Vol. 16, No. 3, 2016, p. 538-543.

[12] SRINIVASSAN, R., RUBAN, W., DEEPANRAJ, A., BHUVANESH, R., BHUVANESH, T. (2020). Effect on infill density on mechanical properties of PETG part fabricated by fused deposition modelling. Materials today proceedings, Vol. 27, Part 2, 2020, p. 1838-1842.

[13] STRATASYS (2018). Spec Sheet [online]. Eden Prairie: Stratasys Ltd. Avaible at: https://www.stratasys.com/materials/search/pla. [2021-01-13].

[14] STRATASYS (2018). Spec Sheet [online]. Eden Prairie: Stratasys Ltd. Avaible at: https://www.stratasys.com/ materials/search/absm30. [2021-01-13]. 